HiberNian LAW JoURNAL, Volume 1, Number 1 (Spring 2000). [Dublin: Law Society of Ireland. 2000. $v$ and 177 pp. Published twice annually. Paperback IR£50 (€63.49) (reduced rates available).]

The principal stated objective of the Founding Editors of this new journal is to provide a forum which integrates the "traditionally distinct activities" of the study and the practice of law. "Multidisciplinary scholarship" will be the editors' means to that end. The Journal aims to promote an increased awareness of the law and its related disciplines among practising and academic lawyers alike, while encouraging increased scholarship by members of the legal community. Only time will tell whether the Journal succeeds in these ambitious objectives. However, it has made an impressive start.

The Journal will also sponsor the annual Hibernian Law Journal Lecture. The recent inaugural lecture by Adrian Zuckerman, ${ }^{1}$ titled "The Second Great English Reform of Civil Justice - A Triumph of Hope over Experience," set an excellent precedent. The annual lecture will contribute both to the Journal's profile and its prestige and in turn will be a further means towards realising the Journal's broader objectives.

The editors intend to tap into a largely unexploited seam of unpublished work by trainee and newly qualified lawyers, junior academics and students. Even if the Journal were to do no more than that it would still perform a great service to Irish legal scholarship. Too much undergraduate and postgraduate research in law schools in Ireland has passed largely unnoticed into storage boxes in attics and ultimately into obscurity for want of an appropriate publishing outlet. The Hibernian Law Journal should ensure that all good quality research and writing receives the wider audience which it deserves.

The format of the Journal is tried and tested. Each biannual issue will contain up to six articles of substantial length and a similar number of short notes or commentaries that address discrete topics.

I like this journal. In their selection of topics and contributors' styles in this inaugural issue, the editors have clearly endeavoured to strike a balance between the academic and the practical, while a number of the contributions cater for both constituencies. Topics addressed in the first issue include the difficulty in reconciling civil forfeiture of the proceeds of crime with the presumption of innocence; a comparative law analysis of aspects of the UNCITRAL Model Law on arbitration; analysis of a narrow point under Article 5(1) of the Brussels (Judgments) Convention; a timely consideration of the South African Truth and Reconciliation Commission; and six shorter pieces on topics ranging from an exploration of the inter-relationship of law, economics and globalisation, to an essay on the relationship between law, criminology and literature, to a review of pragmatic issues such as the 'third party contractual rights' debate in Irish law, a recent development in the limitation of actions, and directors' fiduciary duties in a management buyout.

${ }^{1}$ University of Oxford. 
Nonetheless, the editors' stated objective of integrating the interests of what they acknowledge are traditionally two distinct constituencies carries with it the risk of satisfying neither. It will be important that the editors maintain close contact with their target audience to ensure that the Journal continues to satisfy the need which the editors have identified. In this regard, however, it will be equally important for the Journal to persuade opinion which may be more comfortable with the traditional dichotomy between legal practice and legal scholarship. To challenge such orthodoxy, after all, is the Journal's central mission.

Of course there is scope for improvement. For example, the Journal would benefit from an editorial, a 'voice' which would express its goals and which would in each issue reflect on the state of the relationship between the currently distinct disciplines of legal practice and legal academia, particularly in light of topical issues. The editors might also attempt to promote not merely a descriptive approach with commentary and analysis, but also debate on topical or enduring issues. In doing so, the Journal might consider commissioning authors to provide alternative analyses of and opinions on legal and quasi-legal issues, and actively promote considered and reasoned responses from those of a different view. Such an approach would be more in the nature of a forum, which it is the editors' objective to achieve.

As regards the publication medium, I question whether a paper-based journal is appropriate for the Journal's wider project. In an era of shrinking higher education budgets and (with notable exceptions) a disgraceful level of disinterest on the part of the practising profession in things scholarly, a paper-based journal seems potentially less effective than a web-based publication. The editors must choose either to remain in the highly competitive and relatively low margin commercial market for law journals with a correlation in the Journal's circulation and readership, or secure sponsorship, patronage and advertising to the limited extent necessary to publish the journal on the world wide web and thereby reach a far wider audience. Of course, a successful web-based strategy could embrace paperbased issues of the web journal, such as annual compendiums of the web version, if that was preferred.

I strongly suspect that the editors intend the Journal to be primarily a contribution to scholarship and that profit (as distinct from self-sufficiency) is a lesser consideration. If this is the case, then a web-based rather than a solely paper-based publication could be a more effective medium. The Web Journal of Current Legal Issues, ${ }^{2}$ which soon will 'publish' its thirtieth edition, is an appropriate model. If the objective for the Hibernian Law Journal is to reach as wide an audience as possible, then there is no more cost-effective means of doing so than by way of web publication. This is particularly so as it appears that the target audience for the Journal includes undergraduate and postgraduate students and academics in the increasingly cash-starved higher education sectors, yet who are amongst the most prolific users of the Internet. Similarly, in this day and age it would be a foolhardy

2 http://webjcli.ncl.ac.uk 
practitioner who regarded a piece of research as complete without searching the Internet.

As with every publication, the Journal's credibility is in large part determined by the accuracy of the description of the law which it contains and the quality of the insight offered by the analysts and commentators. The first issue of the Journal impresses in all respects and each contribution is in its own right a substantial piece of work of which the individual authors should be proud. Nonetheless, editorial vigilance will be all the more important in a publication which draws predominantly upon emerging as distinct from established talent. Contributing to that vigilance, the Editorial Advisory Board and the panel of Academic Advisors, each of which includes experts of international renown, will be important sources of support and advice for the editors, and guarantors of the quality of the Journal.

The launch of any new journal is a brave step. The launch of a journal with such aspirations as those of the Hibernian Law Journal is brave, and overdue. Surmounting the many challenges which the Journal faces will be a difficult task for the editors, but the inaugural issue bodes well for the future. I congratulate the editors on their industry, and the contributors on their scholarship - this project deserves to succeed. While a move from a paper journal to a web journal would go a long way to ensure that success, more important will be the continued enthusiasm and hard work of the editors and the continued scholarship of the contributors. I have no doubt about any of these factors.

\section{PETER OSBORNE}

McCann Fitzgerald, Dublin

ENGLISH CRIMINAL JUSTICE IN THE NINETEENTH CENTURY. By David Bentley. [The Hambledon Press, London and Rio Grande, 1998. xv and (with index) $318 \mathrm{pp}$. £45]

When the criminal justice systems of the United Kingdom are preparing for the incorporation into domestic law of the European Convention on Human Rights, and the pace of legislative change in the field of criminal procedure and sentencing has been so unrelenting that the chairman of the Law Commission for England and Wales (Mr Justice Carnwath) has said that "It is too much to hope to persuade governments that justice in relation to sentencing may be best served by leaving the law alone for a while, and making sure that it is accessible and understood", it is timely to reflect upon how the system evolved into its present form. English criminal justice in the nineteenth century provides just such an opportunity.

Until the 1960s most of the principal features of the criminal justice system in England and Wales bore a close resemblance to that which had evolved by the beginning of the century. The police questioned suspects under a nonstatutory code first promulgated by the high court judges in 1912 as the result of complaints by chief constables of inconsistent decisions by judges as to the propriety of cautioning suspects who were being questioned. If the 
defendant was charged with a crime, he was brought before magistrates. Depending upon the gravity of the charge, they either dealt with the offence themselves or sent him for trial to quarter sessions or to the assizes, where he would be tried before a high court judge and a jury.

Save in a small number of cases where the prosecution was carried on by the Director of Public Prosecutions, there was no centralized prosecution system, and most prosecutions were conducted by local solicitors retained for that purpose by the police. If he wished to call an alibi, the defendant did not have to give advance notice of the alibi to the prosecution. The defendant could give evidence on his own behalf, but did not have to do so. If he gave evidence, he could be cross-examined. If he did not give evidence, he could make an unsworn statement, upon which he could not be cross-examined. The verdict of the jury, whether guilty or not guilty, had to be unanimous. In the event of a conviction, the defendant, but not the prosecution, could appeal against conviction or sentence, or both. If the appeal was successful, the court could quash the conviction but not, save in very limited circumstances, order a re-trial.

From this brief description it will be apparent that there have been tremendous changes in the criminal justice system in the closing decades of the twentieth century, yet many of these features, which were accepted as long-established by practitioners in the criminal courts not so long ago, had only been established by the end of the nineteenth century. To take but one example, whilst it is well known that repeated miscarriages of justice in the case of Alfred Beck because of the too-ready acceptance of identification evidence were instrumental in leading to the establishment of a court of criminal appeal in 1907, how many realise that this was the culmination of attempts dating back to the 1840s?

In his masterly and vivid survey of the history of criminal justice in the nineteenth century, David Bentley examines every aspect of the criminal justice system, from the organization and powers of the police to the reform of the rules of criminal evidence. In doing so, he has the great advantage of many years experience of the workings of the criminal justice system as a barrister and a circuit judge, which he combines with a deep knowledge of the mass of historical material which exists in the form of law reports, newspaper reports, as well as parliamentary papers and debates. English Criminal Justice in the Nineteenth Century is a comprehensive survey of every aspect of the criminal justice system which combines the insights of the practitioner with the scholarly approach of the historian. This is no dry historical monologue as the author spares no pains to bring the administration of the criminal law to life, and illuminates many of the less glamorous areas of the system. In the words of a famous newspaper, "all human life is here". We see justices (many of whom were clergymen) sitting in their homes, dubious attorneys touting for work at the Middlesex Sessions, defendants denied copies of the depositions lest they fabricate defences, and of the indictment lest they take a pleading point, child abusers escaping as their victims were often too young to be sworn.

Judge Bentley examines the entire system stage by stage, and as a result provides a detailed account of every aspect of the process from arrest to trial, the conduct of the trial, the operation of the laws of evidence, the summing up, verdict, sentence and such means as existed by which a conviction could 
be challenged. From this it is clear that reforms of the system were only achieved as the result of lengthy campaigns in and out of parliament, in the course of which many proposals were vigorously advocated and rejected, only to be enacted many years later. Many of the arguments advanced in relation to such proposals have a familiar ring. The ad hoc nature of criminal law reform is evident, and frequently gave rise to remarkable inconsistencies. Thus, whilst there were unsuccessful attempts to give prisoners convicted on indictment between 1844 and 1864 a right to appeal, parliament was at the same time giving defendants summarily convicted the right to appeal to quarter sessions.

From the perspective of the student of Irish legal history, one of the attractions of this book is that frequent reference is made to the decisions of the Irish courts, one example demonstrating that the tensions created by the desire of the courts to ensure that a defendant's right to a fair trial was not endangered by adverse pre-trial publicity, and the desire of the press to comment, are not new. In 1846 The Times dismissed a ban imposed by Perrin $\mathbf{J}$ in respect of a treason-felony case he was trying in Dublin with the words "We care as little for the solemn warning of Mr Justice Perryn (sic) as for a veto of the Grand Lama of Tibet". Such problems were not confined to the nineteenth century, and some may remember the proceedings brought in the Northern Ireland High Court against the Daily Express and the Daily Mail as the result of the publication of prejudicial material before the trial of Robert McGladdery, the last man to be hanged in Northern Ireland, reported as $R$ v Beaverbrook Newspapers and others at [1962] NI 15.

This is a work that all who wish to understand how the criminal justice system in these islands evolved should read. If they do, they will do so with profit and pleasure in equal measure.

A.R.Hart

His Honour Judge Hart QC, Recorder of Belfast. 